\title{
Qualidade da carne de peito de frangos de corte recebendo rações com diferentes relações lisina digestível:proteína bruta ${ }^{1}$
}

\author{
Kênia Ferreira Rodrigues ${ }^{2 *}$, Paulo Borges Rodrigues ${ }^{3}$, Maria Cristina Bressan ${ }^{4}$, Adriano \\ Kaneo Nagata ${ }^{2}$, José Humberto Vilar da Silva ${ }^{5}$, Edson Lindolfo da Silva ${ }^{2}$
}

\author{
1 Projeto financiado pela FAPEMIG. \\ 2 Pós-graduação em Zootecnia - UFLA/DZO. \\ ${ }^{3}$ Departamento de Zootecnia/UFLA. \\ ${ }^{4}$ Departamento de Ciência dos Alimentos/UFLA \\ ${ }^{5}$ DAP/CFT/UFPB, Bananeiras - PB e PPGZ, CCA/UFPB, Areia - PB.
}

RESUMO - Avaliou-se o efeito de diferentes relações lisina digestível/proteína bruta (LD:PB) sobre as características químicas e físicas do músculo do peito de frangos de corte, machos, da linhagem Cobb, aos 42 dias de idade. O delineamento foi inteiramente casualizado, segundo um modelo com dois critérios de classificação hierárquica. As aves foram criadas até 21 dias de idade recebendo ração padrão para esta fase e, dos 22 aos 42 dias, alimentas com dietas formuladas com dois níveis de PB (17,0 e 19,5\%) e cinco relações LD:PB, correspondendo a 5,9; 6,4; 6,9; 7,4 e 7,9\% em relação à ração com $17 \%$ de PB e 5,3; 5,7; 6,1; 6,5 e 6,9\% em relação à ração com 19,5\% de PB, totalizando 10 tratamentos com seis repetições. Aos 42 dias de idade, duas aves de cada repetição foram abatidas para coleta de amostras do músculo peitoral. Não foram encontrados efeitos significativos dos tratamentos sobre as características físicas da carne. Nas características químicas, observou-se efeito significativo no nível de 19,5\% de PB, de modo que a PB da carne do peito elevou-se linearmente com o aumento das relações, não sendo constatadas diferenças significativas para as demais características avaliadas. A melhor relação para o nível de $17,0 \%$ de PB foi de 5,9\%, ou 1,34\% de lisina digestível, enquanto, no nível de 19,5\% de PB, a relação de 5,3\% com nível de 1,03\% de lisina digestível apresentou a pior deposição de proteína no músculo do peito. Porém, como as demais variáveis não foram afetadas, a opção de aumentar o teor de lisina digestível para melhorar a PB da carne dependerá do custo desta operação. O nível de proteína na dieta de frangos em crescimento pode ser reduzido até $17,0 \%$ de PB, sem afetar a qualidade da carne do peito, utilizando-se o conceito de proteína ideal.

Palavras-chave: aminoácidos sintéticos, aves, proteína ideal, rendimento

\section{Breast muscle meat quality of broiler chickens fed diets with different digestible lysine/crude protein ratios}

\begin{abstract}
One hundred Cobb male broiler chickens with 42 days old were used to study the effect of different digestible lysine and crude proteins ratios on chemical composition and physical composition of the breast muscle meat A completely randomized design and two hierarquic criteries of classification was used. The birds were raised and fed a basal diet until 21 days old and, from 22 to 42 days, they were fed a diet formulated with two crude protein (CP) levels (17.0 and 19.5\%) and five digestible lysine and CP ratios, 5.9, 6.4, 6.9, 7.4 and $7.9 \%$ for ration with $17.0 \%$ CP and 5.3, $5.7,6.1,6.5$, and $6.9 \%$ for ration with $19.5 \%$ CP, totaling 10 treatments with six replications. At 42 age days, two birds of each replicate were slaughtered for breast muscle meat sample collections. No effects were observed on breast muscle meat for the physical characteristics. In the chemical characteristics, effect in the $19.5 \%$ CP level was observed, in a way that the protein of the breast meat meat llinearly increased as the digestible lysine and CP ratio increases, not being evidenced differences for the others evaluated characteristic. The best ratio for protein deposition in the breast muscle meat in the $17.0 \%$ CP level was 5.9\% (1.34\% digestible lysine), and the worse in the $19.5 \%$ CP level was $5.3 \%$ (1.03\% digestible lysine). However, as the others characteristic was not affected, the option to increase the digestible lysine content to improve the breast muscle meat protein deposition will depend on the cost of this operation. The protein level in the diet of broiler chickens in growth phase can be reduced up to $17.0 \% \mathrm{CP}$, with no effect on breast muscle meat quality of broiler chickens, by using an ideal protein concept.
\end{abstract}

Key Words: ideal protein, poultry, synthetic amino acids, yielding 


\section{Introdução}

A variação da qualidade da carne de frango influencia a preferência do consumidor e pode ser afetada por diversos fatores, como alimentação, linhagem, idade, sexo e processamento de abate.

Segundo Mendes et al. (2003), a produção de filés de peito com especificações rígidas de peso, comprimento e espessura para a exportação e produção de produtos pósprocessados ou para restaurantes de comidas rápidas tem implicações econômicas importantes na rentabilidade da indústria avícola. Além do tamanho e da quantidade de carne obtidos após a desossa, existem outras características de qualidade, como pH, maciez, capacidade de retenção de água, cor e características sensoriais.

Além da genética e do sexo, a nutrição influi no rendimento e na qualidade da carne do peito de frangos de corte, principalmente com relação aos tipos de ingredientes utilizados na fabricação das rações e aos níveis de energia, proteína e aminoácidos da dieta.

Almeida et al. (2002), ao estudarrm o efeito de dois níveis de lisina e do sexo sobre a qualidade da carne de peito de frangos de corte, observaram que os níveis de lisina não afetaram a composição química daquele corte e nem a perda de peso ao cozimento e força de cisalhamento.

Pavan et al. (2003), estudando o efeito de linhagem e do nível de lisina na dieta sobre a qualidade da carne do peito, não encontraram efeito destes sobre a perda de peso por cozimento e força de cisalhamento.

Diversos pesquisadores (Summers \& Leeson, 1985; Summers et al., 1992, citados por Holsheimer \& Ruesink, 1993) relataram que o nível de lisina da dieta afeta a composição química da carcaça, sendo que níveis mais altos desse aminoácido proporcionam maiores porcentagens de proteína na carcaça, resultados não confirmados por Almeida et al. (2002).

Tesseraud et al. (2001), avaliando o efeito da deficiência de lisina em diferentes linhagens de frangos de corte com 3 semanas de idade, observaram efeito da deficiência de lisina sobre o crescimento e peso dos músculos peitorais e aumento na taxa de síntese e quebra protéica no músculo Pectoralis, não ocorrendo o mesmo no músculo Sartorius. A resposta à deficiência de lisina foi diferenciada, de modo que as linhagens melhoradas para maior rendimento de peito apresentaram-se mais preparadas para responder à modificação nos nutrientes de suas dietas.

Como relatado anteriormente, a capacidade de retenção de água, que é a capacidade do músculo e de produtos cárneos em manter a água ligada em condições específicas, é de suma importância, pois está relacionada ao aspecto da carne antes do cozimento, ao comportamento durante a cocção e à palatabilidade do produto (Bressan, 1998).

Objetivou-se verificar o efeito das diferentes relações lisina digestível/proteína bruta (LD:PB), utilizadas nas dietas dos frangos no período de 22 a 42 dias, sobre as qualidades físico-químicas da carne de peito, principal corte comercializado na cadeia de carne de aves.

\section{Material e Métodos}

Este experimento foi conduzido no Setor de Avicultura do Departamento de Zootecnia da Universidade Federal de Lavras (UFLA), Lavras, MG. Foram utilizados 1.200 pintos de corte machos, da linhagem comercial Cobb, com 21 dias de idade e peso médio inicial de $879,6 \pm 17 \mathrm{~g}$. As aves foram criadas até 21 dias de idade no galpão experimental, dividido em boxes com piso coberto com cama de maravalha. Cada boxe continha um bebedouro pendular e um comedouro tubular, onde as aves receberam ração à base de milho e farelo de soja com níveis nutricionais recomendados, para essa fase, de acordo com Rostagno et al. (2000).

Aos 21 dias de idade, as aves foram uniformizadas por peso e alojadas nos boxes experimentais.

Foram estudadas diferentes relações LD:PB da ração, considerando a exigência das aves adotadas nas tabelas brasileiras (Rostagno et al., 2000), o que culminou em teores muito elevados de lisina digestível nas dietas de alta PB. Como o objetivo foi estudar diferentes teores de PB, adotou-se, então, um modelo com dois critérios de classificação hierárquica: dois níveis de PB (17,0 e 19,5\%) e cinco diferentes relações (cinco níveis de lisina digestível) dentro de cada nível de proteína: 5,9; 6,4; 6,9, 7,4 e 7,9\% para 17,0\% de PB e 5,3; 5,7; 6,1; 6,5 e 6,9\% para 19,5\% de PB. Desta forma, a composição nutricional correspondeu aos seguintes níveis de lisina digestível: $17,0 \%$ de PB - 1,00; 1,09; 1,17; 1,26 e 1,34\% e 19,5\% de PB-1,03; 1,11; 1,19; 1,27 e 1,34\%.

Cada ração foi fornecida a 20 aves de cada uma das seis repetições. Os níveis de $\mathrm{PB}$ foram fixados segundo as recomendações de Rostagno et al (2000) e a relação LD:PB, a partir daquela indicada por Gonzáles et al. (1997) para lisina total:PB (5,5\%).

As rações (Tabelas 1 e 2) foram isoenergéticas (3.100 kcal de EM/kg) e constituídas basicamente de milho e farelo de soja; os níveis nutricionais dos demais nutrientes seguiram as recomendações de Rostagno et al. (2000) e as rações foram formuladas com base na proteína ideal indicada por estes autores.

Para os cálculos dos teores de PB e de energia metabolizável das rações, não foram considerados os valores protéico e 
energético dos aminoácidos. Ração e água foram fornecidos à vontade e a luz diária natural, sem luz durante a noite.

Aos 42 dias de idade, foram abatidas duas aves por parcela experimental, seguindo o peso médio do lote, totalizando 120 aves. As aves foram identificadas, pesadas e abatidas por deslocamento cervical, realizando-se a sangria e a retirada de penas, cabeça e vísceras, e então pesadas novamente. Em seguida, foram retirados e pesados, individualmente, os cortes, separando-se os filés de peito, que foram congelados a $-10^{\circ} \mathrm{C}$. As amostras utilizadas nas análises químico-fisicas foram descongeladas a $4^{\circ} \mathrm{C}$ por 24 horas. Também foram analisadas amostras de carcaças de frangos com 21 dias de idade para os cálculos das taxas de retenção de proteína e deposição de lipídeos neste período.
As análises químicas (umidade, extrato etéreo, proteína e cinzas) e físicas foram realizadas no Laboratório de Tecnologia de Carnes do Departamento de Ciências dos Alimentos da UFLA, em duplicatas, segundo o método preconizado pela AOAC (1990). A avaliação da coloração

Tabela 1 - Composição nutricional dos ingredientes das rações experimentais $^{1}$

\begin{tabular}{lcccc}
\hline Ingrediente & MS & PB & Ca & P disponível \\
\hline Milho & 86,51 & 9,0 & $0,03^{*}$ & $0,08^{*}$ \\
Farelo de soja & 87,77 & 45,65 & $0,24^{*}$ & $0,18^{*}$ \\
Fosfato bicálcico & & & 24,07 & 18,63 \\
Calcário calcítico & & & 38,67 & \\
\hline
\end{tabular}

${ }^{1}$ Análises realizadas no Laboratório de Pesquisa Animal DZO-UFLA. * Dados compilados de Rostagno et al. (2000).

Tabela 2 - Composição em ingredientes das dietas experimentais da fase de crescimento

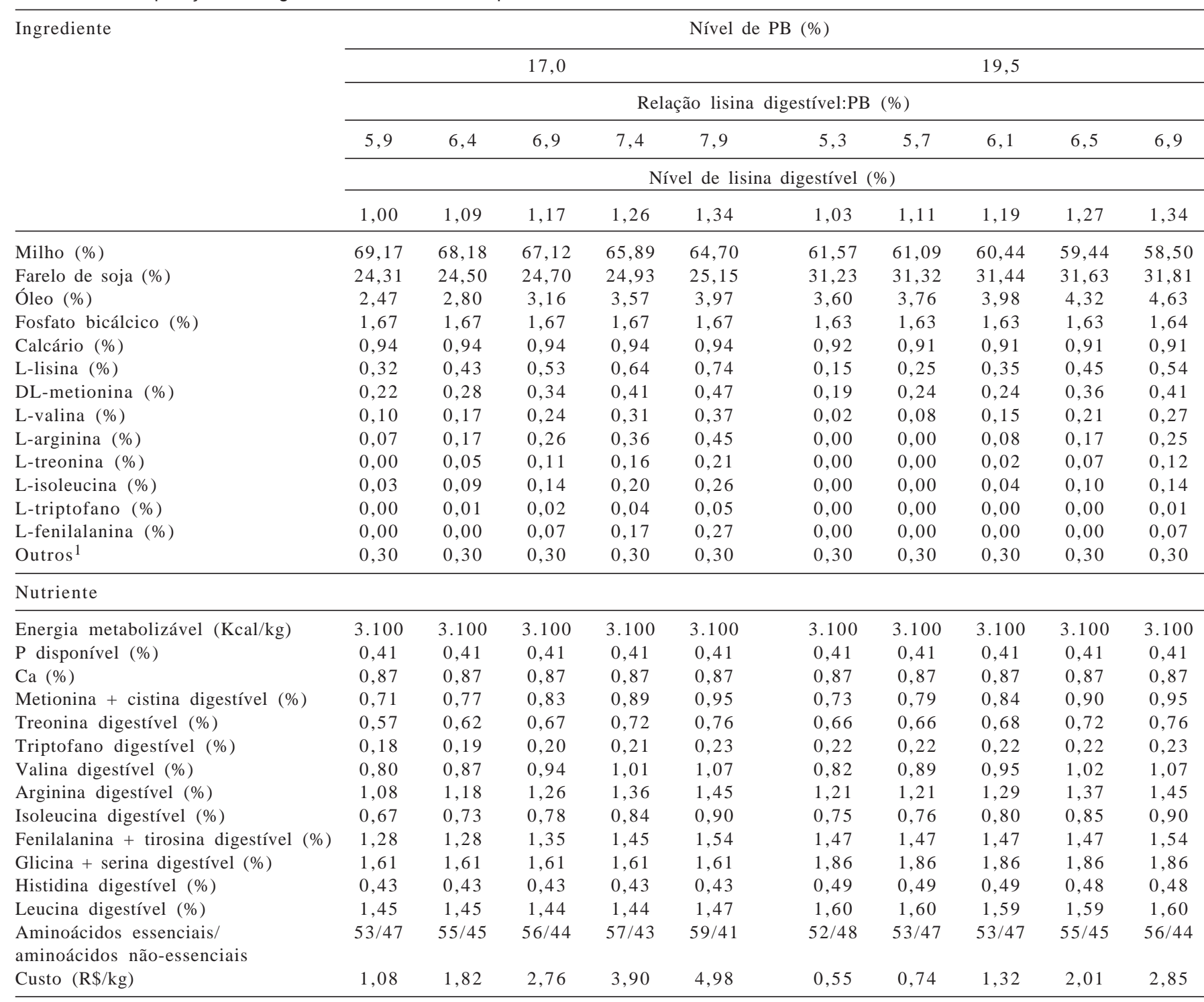

${ }_{1}^{1}$ Sal, premix mineral e vitamínico (Fornecimento por kg de ração: $70 \mathrm{mg}$ Zn, $50 \mathrm{mg} \mathrm{Fe,} \mathrm{8,5} \mathrm{mg} \mathrm{Cu,} \mathrm{0,2} \mathrm{mg} \mathrm{Co,} 75$ mg Mn e 1,5 mg l; 3,3 mg vit. B $633 \mathrm{mg}$ Nicotinamida, $2,2 \mathrm{mg}$ vit. $B_{1}, 16 \mathrm{mcg}$ vit. $B_{12}, 6 \mathrm{mg}$ vit. $B_{2}, 1 \mathrm{mg}$ de ac. fólico, $13 \mathrm{mg}$ de ac. pantotênico, $2,5 \mathrm{mg}$ vit. $K_{3}, 30 \mathrm{mg}$ vit. E, 1,2 mg vit. A, 2,2 mg vit $\mathrm{D}_{3}$, cloreto de colina $(70 \%)$, inerte. 
foi realizada pelo Sistema CIELAB ( $\mathrm{L}^{*}=$ luminosidade, $\mathrm{a}^{*}=$ teor de vermelho e $\mathrm{b}^{*}=$ teor de amarelo) com colorímetro (Minolta CR-200b), sendo a leitura realizada em três pontos distintos da musculatura, utilizando-se os valores médios.

$\mathrm{Na}$ análise da perda por cozimento (PPC), foi utilizada a porção esquerda dos músculos peitorais. As amostras foram pesadas, envolvidas em papel-alumínio e colocadas para assar em chapa pré-aquecida a $150^{\circ} \mathrm{C}$. Ao alcançarem a temperatura interna de $35^{\circ} \mathrm{C}$, as amostras foram viradas e mantidas até atingirem a temperatura interna de $72^{\circ} \mathrm{C}$. Em seguida, foram resfriadas à temperatura ambiente. A PPC para cada músculo foi calculada pela média (\%) das diferenças de peso entre as amostras antes do cozimento e após o resfriamento.

A força de cisalhamento $(\mathrm{FC}=$ maciez $)$ foi determinada utilizando-se as amostras da PPC. De cada amostra foram extraídas, no sentido da fibra, quatro amostras ( $1 \mathrm{~cm}$ de cada lado e $3 \mathrm{~cm}$ de comprimento) na forma de paralelepípedos. A FC foi medida pela secção dos pedaços, usando o aparelho Instron M2318, acoplado ao Warner-Bratzler, com a escala variando de 0 a $50 \mathrm{kgf}$ (Froming et al., 1978).

As análises estatísticas foram realizadas utilizando-se o pacote computacional SAEG (UFV, 1993). A análise de variância foi realizada com base no método dos quadrados mínimos e no modelo com dois critérios de classificação hierárquica, conforme apresentado a seguir:

$$
\mathrm{y}_{\mathrm{ijk}}=\mu+\mathrm{P}_{\mathrm{i}}+\mathrm{R}_{\mathrm{j}} / \mathrm{P}_{\mathrm{i}}+\mathrm{e}_{\mathrm{ijk}} \text {, }
$$

em que $\mathrm{y}_{\mathrm{ijk}}=$ observação em cada repetição, com $\mathrm{i}=1,2$; $\mathrm{j}=1,2,3,4$ e 5 e $\mathrm{k}=1,2,3,4,5$ e $6 ; \mu$ = média geral; $\mathrm{P}_{\mathrm{i}}=$ efeito do nível de PB i; $R_{j} / P_{i}=$ efeito da relação lisina digestível: $P_{j}$, dentro do nível de PB i; $\mathrm{e}_{\mathrm{ijk}}=$ erro associado a cada observação, que por pressuposição é NID $\left(0, \delta^{2}\right)$.
Dentro de cada nível de PB estudado, foi realizada análise de regressão polinomial para determinar a melhor relação LD:PB, optando-se pelo modelo que melhor se ajustasse aos dados.

\section{Resultados e Discussão}

Não foram encontradas diferenças $(\mathrm{P}>0,05)$ entre os efeitos das diferentes relações LD:PB sobre os teores de umidade, extrato etéreo e cinzas, sendo os resultados obtidos semelhantes àqueles encontrados por Almeida (2002), que encontrou média de 73,95; 0,94 e 1,31\%, respectivamente para umidade, extrato etéreo e cinzas (Tabela 3). A porcentagem de $\mathrm{PB}$ no peito elevou-se linearmente $(\mathrm{P}<0,01)$ com o aumento das relações dentro do nível de 19,5\% de $P B$, sendo que o nível de $17,0 \%$ de $P B$ não apresentou efeito significativo ( $\mathrm{P}>0,05)$, com deposição máxima na relação 6,9\% e nível de 1,34\% de lisina digestível (Figura 1).

Os resultados de $\mathrm{PB}$ encontrados confirmaram os dados publicados por diversos autores (Holsheimer \& Ruesink, 1993; Summers \& Leeson, 1985; Summers et al., 1992), que afirmaram que os níveis mais altos desse aminoácido proporcionam maiores porcentagens de proteína na carcaça.

Almeida et al. (2002) observaram que o nível de PB $(22,27 \%)$ não foi afetado pelos níveis de lisina utilizados (1,00 e 1,10\% de lisina), resultado diferente dos encontrados neste trabalho.

Não houve diferenças $(\mathrm{P}>0,05)$ entre os níveis de $\mathrm{PB}$ estudados para todas as variáveis estudadas, mostrando haver maior influência dos teores de aminoácidos nas

Tabela 3 - Efeito de diferentes relações lisina digestível:proteína bruta (LD:PB) sobre umidade (UM), extrato etéreo (EE), PB e cinzas (CZ) da carne do peito de frangos de corte (42 dias de idade)

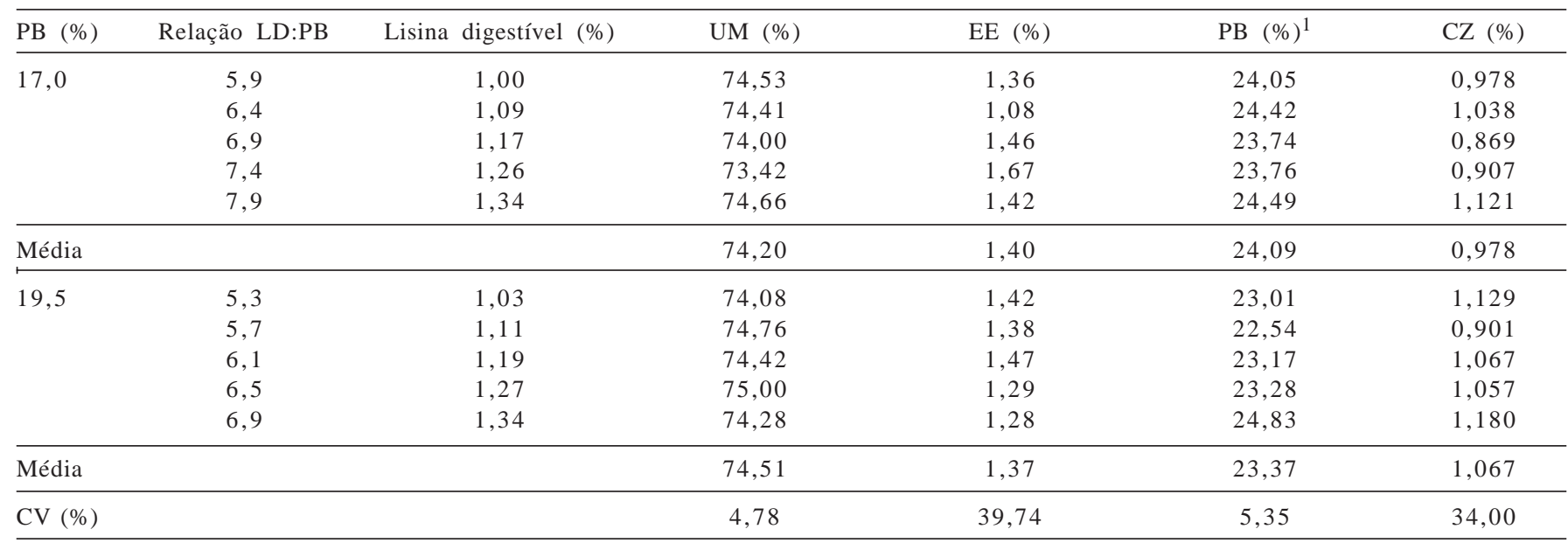

.${ }^{1}$ Efeito linear dentro do nível de $19,5 \%$ de $P B(P<0,01)$. 
19,5\% de $\mathrm{PB}$

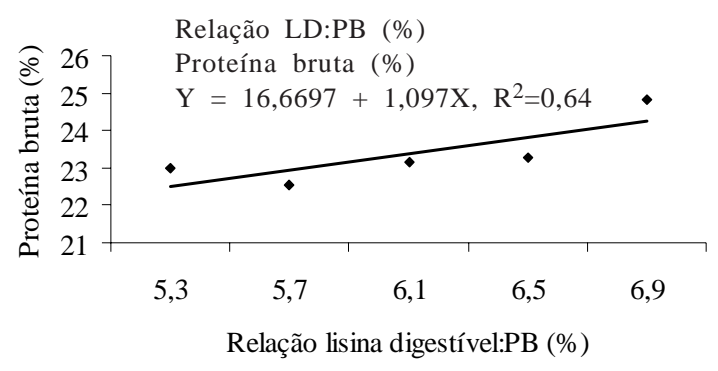

Figura 1 - Teores de proteína bruta nos filés de peito de frangos de corte recebendo rações com diferentes relações lisina digestível:proteína bruta (LD:PB) aos 42 dias de idade. dietas do que do nível de PB sobre as características físicas da carne do peito.

Não foram observados efeitos significativos $(\mathrm{P}>0,05)$ das diferentes relações sobre a perda de peso por cozimento, força de cisalhamento e cor do músculo do peito das aves. A literatura cita valores que variam entre 21,66 e 29,03\% para perda de peso por cozimento para carne de peito. Bressan (1999) e Mendes et al. (2003), citados por Almeida et al. (2002), encontraram valor médio de 22,58\% de perda de peso aos 42 dias e força de cisalhamento de $4,70 \mathrm{kgf} / \mathrm{g}$, enquanto Pavan et al. (2003) encontraram valores de 1,91 a 2,23 kgf/g. Como pode ser observado na Tabela 4, a média de força de cisalhamento encontrada neste experimento foi de $3,5 \mathrm{kgf} / \mathrm{g}$,

Tabela 4 - Efeito de diferentes relações lisina digestível:proteína bruta (LD:PB) sobre perda de peso com cozimento (PPC), cor (L, a e b) e força de cisalhamento (FC) da carne do peito de frangos de corte (42 dias de idade)

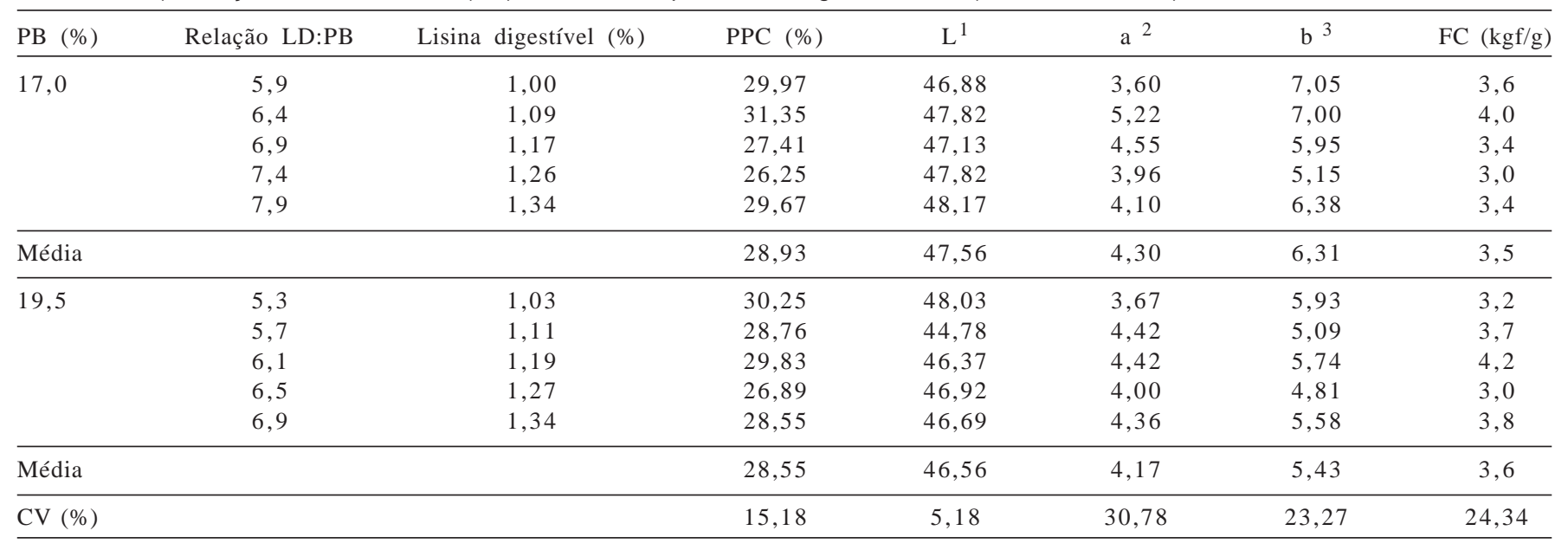

${ }^{1}$ luminosidade; ${ }^{2}$ tendência para o vermelho; ${ }^{3}$ tendência para o amarelo.

valor intermediário entre os apresentados por Pavan et al. (2003) e inferior ao de 7,5 kgf, utilizado como referência por alguns autores, acima do qual a carne seria considerada dura (Lyon et al., 1995).

Quanto à cor, pode-se observar maior tendência para o amarelo (valores superiores de b* em relação ao $a^{*}$ ), reforçando as características da musculatura do peito de aves, quando comparada a outras, como carne de ovinos, por exemplo, em que $L^{*}-38,00 ; a^{*}-12$ a $15 ; b^{*}-3$ a 5 (Souza et al., 2004).

A luminosidade da carne, por variar mais em função da umidade da carne, é influenciada pela idade da ave, o que não ocorreu neste trabalho, no qual as aves tinham a mesma idade, apresentando índice de luminosidade de 47,56 e 46,56, respectivamente, para os níveis de 17,0 e 19,5\% de PB.

\section{Conclusões}

A melhor relação para o nível de 17,0\% de PB foi de 5,9\%, enquanto, no nível de 19,5\% de PB, considerando a deposição de proteína na carne do peito, indica-se a relação de 6,9\% com nível de 1,34\% de lisina digestível. Ressalta-se que o nível de lisina digestível será determinado considerando-se o custo dos aminoácidos sintéticos e demais variáveis. A relação de 5,3\%, ou seja, o nível de $1,03 \%$ de lisina digestível, atende tanto as necessidades da ave nesta fase quanto a qualidade da carne de peito. O nível de proteína na dieta de frangos em crescimento pode ser reduzido até $17,0 \%$ de $P B$, sem afetar a qualidade da carne do peito, utilizando-se o conceito de proteína ideal. 


\section{Literatura Citada}

ALMEIDA, I.C.L.; MENDES, A.A.; OLIVEIRA, E.G. et al. Efeito de dois níveis de lisina e do sexo sobre o rendimento e qualidade da carne de peito de frangos de corte. Revista Brasileira de Zootecnia, v.31, n.4, p.1744-1752, 2002.

ASSOCIATION OF THE OFFICIAL METHODS OF ANALYSIS AOAC. Methodos of analysis of the Association of Official Analytical Chemists. 14.ed. Washinton, D.C.: 1990. 1015p.

BRESSAN, C. Efeito dos fatores pré-abate sobre a qualidade dos peitos de frango. Campinas: Universidade de Campinas, 1998. 179p. Tese (Doutorado em Tecnologia de Alimentos) Universidade de Campinas, 1998.

FROMING, G.W.; BABJL, A.S.; MATHER, F.B. The effect os preslaugther temperatures, stress, struggle and anesthetization on color and textural characteristics of turkey muscle. Poultry Science, v.57, n.3, p.630-633, 1978.

GONZÁLEZ, R.R.F.; CAMACHO, D.Y.; CUARÓN, J.A. Requerimiento de proteína cruda en función a lisina, en dietas formuladas a proteína ideal para pollos de engorda. In: REUNIÓN NACIONAL DE INVESTIGACIÓN PECUARIA, 33., 1997, Veracruz. Memórias... Veracruz: 1997. (CD-ROM).

HOLSHEIMER, J.P.; RUESNIK, E.W. Effect on performance, carcass composition, yield and financial return of dietary energy and lysine levels in starter and finisher diets fed to broilers. Poultry Science, v.72, n.5, p.806-815, 1993.

LYON, C.F.; HAMM, D.E.; THOMSON, J.E. pH and tenderness of broiler breast meat deboned various times after chilling. Poultry Science, v.64, n.2, p.307-310, 1985.

MENDES, A.A.; MOREIRA, J.; GARCIA, R.G. Qualidade da carne de peito de frango de corte. Revista Nacional da Qualidade da Carne, v.28, n.317, 2003.
PAVAN, A.C.; MENDES, A.A.; OLIVEIRA, E.G. et al. Efeito da linhagem e do nível de lisina da dieta sobre a qualidade da carne do peito de frangos de corte. Revista Brasileira de Zootecnia, v.32, n.6, p.1732-1736, 2003.

ROSTAGNO, H.S.; ALBINO, L.F.T.; DONZELE, J.L. et al. Tabelas brasileiras para aves e suínos (Composição de alimentos e exigências nutricionais). Viçosa, MG: Editora UFV, 2000. 141p.

SOUZA, X.R.; BRESSAN, M.C.; PÉREZ, J.R.O. et al. Efeitos do grupo genético, sexo e peso ao abate sobre as propriedades físico-quícas da carne de cordeiros em crescimento. Ciência e Tecnologia dos Alimentos, v.24, n.4, p.543-549, 2004.

SUMMERS, J.D.; LEESON, S. Broiler carcass composition as affected by amino acid supplementation. Canadian Journal of Animal Science, v.65, n.3, p.717-723, 1985.

SUMMERS, J.D.; SPRATT, D.; ATKINSON, J.L. Broiler weigth gain and carcass composition when fed diets varying in amino acid balance, dietary energy, and protein level. Poultry Science, v.71, n.2, p.263-271, 1992.

TESSERAUD, S.; TEMIN, S.; LÊ BIHAN-DUVAL, E. et al. Increased responsiveness to dietary lysine deficiency of pectoralis major muscle protein turnover in broilers selected on breast development. Journal of Animal Science, v.79, n.4, p.927933, 2001.

UNIVERSIDADE FEDERAL E VIÇOSA - UFV. SAEG - Sistema para análises estatística e genética. Viçosa, MG: Central de Procesamento de Dados - UFV - CPD, 1993. 59p.

Van CAUWENBERGHE, S.; BURNHAM, D. New developments in amino acid and protein nutrition of poultry, as related to optimal performance and reduced nitrogen excretion. In: EUROPEAN SYMPOSIUM POULTRY NUTRITION, 13. 2001, Blankenberge. Proceedings... Blankenberge: 2001. (CD-ROM). 